\title{
Intelligent Analysis of the Ecological State of Environment with Application of Distributed Expertise (on the Example of Bryansk Region)*
}

\author{
Emilia Geger 1[0000-0003-0393-4274], Aleksandr Podvesovskii 2[0000-0002-1118-3266], \\ Oksana Mikhaleva 2[0000-0001-6374-2827] and Anton Korsakov 2[0000-0002-4609-0246] \\ ${ }^{1}$ Bryansk Clinicodiagnostic Center, Bryansk, Russia \\ emiliya geger@mail.ru \\ ${ }^{2}$ Bryansk State Technical University, Bryansk, Russia \\ apodv@tu-bryansk.ru, gordonmi@mail.ru, korsakov_anton@mail.ru
}

\begin{abstract}
The paper considers the problem of assessing the ecological state of the environment in the region. An approach to the intelligent analysis and estimation of anthropo-technogenic pollution of a territory with the application of integral indicators which take into account environmental pollution is proposed. To estimate the integral indicator parameters, distributed group expertise technology is used, supporting a mechanism for control of expert estimates consistency, taking into account experts' competency in the relevant subject areas. Using the proposed approach, the problem of risk assessment of environmental impact of chemical air pollutants has been solved. Methods for control of expert estimates consistency based on the procedure of feedback with experts made it possible to increase the reliability of evaluation results and also to decrease the influence of a random expert error on the final assessment. The obtained aggregated risk estimates were used to construct, calculate and visualize the integral indicator of radioactive and chemical contamination of the districts of Bryansk region.
\end{abstract}

Keywords: Environment, Anthropo-Technogenic Pollution, Integral Indicator of Pollution, Expert Estimates, Group Expertise, Consistency of Expert Estimates, Distributed Environment.

\section{Introduction}

Today, scientific problems of monitoring and evaluating biological and medical consequences of anthropo-technogenic pollution of the environment are a priority for state policy in all economically developed countries $[1,2]$.

Copyright (C) 2020 for this paper by its authors. Use permitted under Creative Commons License Attribution 4.0 International (CC BY 4.0).

* The reported study was funded by RFBR, project number 20-04-60185. 


\section{E. Geger, A. Podvesovskii, O. Mikhaleva, et. al.}

Analysis of environmental pollution using traditional statistical methods is not always possible due to the lack of unity and required accuracy of measurement results of environmental pollution indicators used in monitoring and the absence of a unified structured system for assessing environmental pollution [3]. Parametric and nonparametric statistical methods have fairly strict assumptions - general homogeneity of observation conditions must be maintained, samples must be sufficiently representative, with clear quantitative characteristics, etc. In cases where such assumptions cannot be made, it is proposed to move from statistical methods to intelligent decisionmaking support technologies. In particular, it is proposed to use methods of multicriteria optimization in conjunction with the technology of distributed expertise to identify and estimate the parameters of this method.

Multi-criteria optimization is a group of decision-making methods. These methods consist in finding an optimal solution that satisfies several criteria not reducible to each other, based on a certain optimality principle.

An expert approach is based on the use of the collective opinion of experts (i.e., specialists in the relevant subject areas) in the preparation and decision-making process. Expert opinions are usually expressed partly in quantitative and partly in qualitative forms. Expert methods are used in situations where the choice, justification and assessment of the consequences of decisions cannot be performed on the basis of accurate calculations. The current level of information and communication technologies makes it possible to organize distributed interaction of experts among themselves, as well as with decision-makers and managers of expertise, using modern communication networks, primarily the Internet. Due to the above circumstances, a new phenomenon called networked expertise is emerging. Within its framework, expert networks and network expert communities are being created and are actively developing [4].

Due to the heterogeneity of environmental statistical data in estimating anthropotechnogenic pollution, it seems difficult to fully assess the risk of a specific impact of pollutants on the environment. Therefore, in this study, we have applied an approach to estimating the environmental situation on the example of Bryansk region using multi-criteria optimization methods together with the distributed expertise technology.

Earlier in [5,6], integral criteria were proposed for each type of pollution based on the method of expert estimates. Then they were summed up for the districts of Bryansk region, taking into account weight coefficients for the corresponding type of pollution in the district.

Transferring the decision-making process to a distributed environment complicates the use of traditional methods of organizing expert activity [7]. Therefore, it is required to develop new effective methods for supporting group expertise taking into account peculiarities of participants' geographically-distributed interaction in this process.

In this paper, it is proposed to consider implementation features of the technology for supporting group expertise in a distributed environment aimed at estimating the ecological state of the environment on the example of Bryansk region. 


\section{Description of the group expertise methods in a distributed environment}

The purpose of applying networked expertise in this study is to assess the importance (priority, hazard) of chemical and radiation pollutants for each environmental media (air, water, soil) and food. One of the main tasks of expert estimates is to obtain weight coefficients of each of the specific environmental media pollutants. A separate subtask is to estimate the degree of influence of a particular pollutant on the environmental media based on the exposure hazard.

To obtain an objective expert opinion, each of the conditions must be met:

- availability of an expert group consisting of experts with subject matter expertise;

- availability of an analytical group with knowledge of mathematical apparatus for obtaining and processing expert information.

In general, preparation and conduct of the networked expertise includes such stages as formation of an expert group, choice of a type and method of obtaining expert estimates, assessment of expert estimates consistency, and determination of the final (aggregated) consistent expert estimate. In addition, an important task arises related to assessing experts' competency in the relevant subject area and taking it into account in the estimation model, both at the stage of assessing expert estimates consistency and at the stage of forming the final assessment. Solution to the listed problems is based on the use of information technology for group expertise support in a distributed environment [8], together with models and methods for control of expert estimates consistency [9].

The first step after obtaining a set of individual estimates of objects is to check the consistency of this set taking into account the experts' competency. When working with numerical (cardinal) estimates, the consistency of the set of individual estimates $W=\left\{w_{1}, \ldots, w_{m}\right\}$ can be evaluated using a spectral coefficient:

$$
K_{S}(W)=\left(1-\frac{\sum_{k=1}^{p} \sigma_{k}\left|k-\sum_{k=1}^{p} k \sigma_{k}\right|-\sum_{k=1}^{p} \sigma_{k} \ln \left(\sigma_{k}\right)}{G \sum_{k=1}^{p}|k-(p+1) / 2| \ln (p)}\right) z,
$$

where $k$ is the sum of the coefficients of experts' relative competency $c_{i}$; their estimates are represented by the $k$-th scale mark; $G=m / \ln (m) p \ln (p)$ is a scale factor;

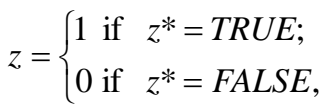

$$
\begin{aligned}
& z^{*}=\overline{[k(1)=1]} \vee \overline{[k(q)=p]} \underset{d=1}{q-1} \overline{\left[\sigma_{k(d)}=\sigma_{k(d+1)}\right]} \vee_{d=1}^{q-1} \overline{[k(d)-k(d+1)=\mathrm{const}]}
\end{aligned}
$$


Expression (3) is a Boolean function that specifies the necessary and sufficient conditions for the equality of the consistency coefficient (1) to zero. In this case, $q$ is the number of subgroups of experts who gave the same estimates, $k(d)$ is the number of the scale mark corresponding to the estimate received from the experts of the $d$-th subgroup $(d=1, \ldots, q), \sigma_{k(d)}$ is the sum of the competency coefficients of the experts of the $d$-th subgroup (a more detailed description can be found in [10]).

After calculating the consistency coefficient, it is necessary to compare its value with the threshold values $T_{O}$ (detection threshold) and $T_{U}$ (application threshold), and to assess whether the consistency degree of the set of expert estimates is sufficient to be used to calculate the aggregated estimate [10]. The comparison result can be used to decide on the possibility of further use of the set. If the consistency coefficient is higher than the application threshold, then the consistency of the set of expert estimates is sufficient. If the consistency coefficient is between the detection threshold and the application threshold, then the set of expert estimates contains information, but its consistency degree is insufficient to determine the aggregated estimate. If the consistency coefficient is below the detection threshold, then the set of expert estimates does not contain information, and it is necessary to suggest that all the experts should revise their estimates of the objects or to make a full or partial replacement of the expert group.

Considering this fact, we can say that one of the important aspects of organizing group expertise in a distributed environment is the control of expert estimates consistency based on conducting a feedback procedure with experts [9]. This procedure consists in contacting selected experts with a request for the possibility of changing their estimates and recommendations aimed at increasing the consistency of the set of individual estimates. If the expert agrees to change his estimate, then, based on the results of the change, the consistency coefficient is recalculated. When working with numerical (cardinal) estimates, at each step, an expert is selected for whom the largest value is

$$
\delta_{i}=\frac{\left|w_{i}-w_{0}\right|}{c_{i}},
$$

characterizing the deviation of the estimate given by him from the average estimate in the group. In this case, expert's competency is taken into account - with a decrease in the expert's competency, the degree of trust in his opinion decreases when it differs from the mean group one. Here, $w_{0}$ is the average estimate calculated taking into account the experts' competency:

$$
w_{0}=\sum_{i=1}^{m} c_{i} w_{i} .
$$




\section{Solving the problem of expert estimation of the degree of influence of a pollutant on a pollution object}

Let us consider, for example, the problem of expert estimation of the risk of the impact of chemical air pollutants on the environment. The expertise objects are 15 chemicals (CO, $\mathrm{NO}, \mathrm{NO}_{2}$, ammonia, ethanol, suspended solids, formaldehyde, acetic acid, hydrogen fluoride, manganese, iron oxide, hydrogen sulfide, petroleum hydrocarbons, xylene, toluene).

To analyze and estimate the objects, an expert group was formed, which included six independent experts specializing in various environmental aspects. The experts' competency was assessed on the basis of their level of knowledge in the expertise subject area. The corresponding competency coefficients are presented in Table 1.

Table 1. Experts' competency coefficients.

\begin{tabular}{|l|c|c|c|c|c|c|}
\hline Expert's number, $i$ & 1 & 2 & 3 & 4 & 5 & 6 \\
\hline $\begin{array}{l}\text { Competency } \\
\text { coefficient, } c_{i}\end{array}$ & 0,286 & 0,238 & 0,190 & 0,143 & 0,095 & 0,048 \\
\hline
\end{tabular}

A numerical rating scale with values from 1 (least influence) to 15 (greatest influence) was chosen as the estimation scale.

To process the results of expert estimation, the initial spectral consistency coefficients of each obtained expert estimate set were calculated, the detection and application thresholds were determined. In cases where the consistency coefficient value appeared to be less than the value of the application threshold, the method of increasing the consistency was used based on the procedure of feedback with experts. Table 2 presents the results of increasing the consistency, as well as the final aggregated estimates and the corresponding ranks of the expertise objects.

Analysis of the results of solving the estimation problem showed the following.

As a result of increased consistency, it was possible to ensure complete consistency of expert estimates for objects such as manganese, xylene, and toluene - the final consistency coefficient exceeds the application threshold (the corresponding cells in the table are highlighted in green). For formaldehyde, the consistency coefficient of estimates exceeded the application threshold from the beginning, which allows us to speak about the consistency of the initial set of estimates for this object.

The initial coefficient value of the expert estimate consistency for four objects (CO, ammonia, acetic acid, petroleum hydrocarbons) did not exceed the detection threshold. This means that the consistency of the corresponding estimates is below the acceptable threshold (the corresponding cells in the table are highlighted in red). Consistency increasing procedure led to an increase in the consistency coefficient, but the application threshold was not exceeded. Also, it was not possible to ensure high consistency of expert estimates for the suspended solid object, although the initial value of the consistency coefficient exceeded the detection threshold. The cells in the table corresponding to the situation when the estimates consistency coefficient is between the detection and application thresholds are highlighted in yellow. 
6 E. Geger, A. Podvesovskii, O. Mikhaleva, et. al.

Table 2. Results of solving the estimation problem.

\begin{tabular}{|c|c|c|c|c|c|}
\hline No. & \begin{tabular}{|c|} 
Chemical \\
substances (objects)
\end{tabular} & $\begin{array}{l}\text { Initial consistency } \\
\text { coefficient, } K_{S}(W)\end{array}$ & $\begin{array}{c}\text { Final consistency } \\
\text { coefficient, } K_{S}^{\prime}(W)\end{array}$ & $\begin{array}{l}\text { Aggregated } \\
\text { estimate } \\
\text { (weight), } w_{0}\end{array}$ & Rank \\
\hline 1 & $\mathrm{CO}$ & 0,290 & 0,470 & 8,569 & 9 \\
\hline 2 & $\mathrm{NO}$ & 0,650 & 0,790 & 9,334 & 8 \\
\hline 3 & $\mathrm{NO}_{2}$ & 0,670 & 0,770 & 10,286 & 5 \\
\hline 4 & Ammonia & 0,350 & 0,507 & 6,142 & 12 \\
\hline 5 & Ethanol & 0,562 & 0,796 & 3,620 & 14 \\
\hline 6 & Suspended solids & 0,469 & 0,570 & 6,382 & 10 \\
\hline 7 & Formaldehyde & 0,864 & & 13,713 & 1 \\
\hline 8 & Acetic acid & 0,404 & 0,529 & 6,331 & 11 \\
\hline 9 & Hydrogen fluoride & 0,517 & 0,733 & 12,237 & 2 \\
\hline 10 & Manganese & 0,563 & 0,818 & 4,095 & 13 \\
\hline 11 & Iron oxide & 0,554 & 0,702 & 3,428 & 15 \\
\hline 12 & Hydrogen sulfide & 0,593 & 0,752 & 11,236 & 3 \\
\hline 13 & $\begin{array}{c}\text { Petroleum } \\
\text { hydrocarbons }\end{array}$ & 0,426 & 0,617 & 11,093 & 4 \\
\hline 14 & Xylene & 0,602 & 0,876 & 9,662 & 6 \\
\hline 15 & Toluene & 0,549 & 0,840 & 9,571 & 7 \\
\hline \multicolumn{2}{|c|}{$\begin{array}{l}\text { Detection threshold } \\
\text { Application threshold }\end{array}$} & \multicolumn{4}{|c|}{$\begin{array}{l}T_{O}=0,429 \\
T_{U}=0,822\end{array}$} \\
\hline
\end{tabular}

For all the other objects, the initial value of the consistency coefficient exceeded the detection threshold. As a result of the consistency increase, it was possible to make it close to the application threshold though not exceeding it. This also allows us to conclude that the final expert estimates for these objects are sufficiently consistent.

In the course of increasing the consistency, reasons for the low consistency of estimates of some objects were identified. It was found that, in most cases, the opinions of experts with numbers 5 and 6 , who had the least competence in the subject area, differed significantly from the other experts' opinions. In this regard, it was decided to replace these two experts with one new expert whose competence roughly coincides with the competence of expert 4 and is estimated by the coefficient $c_{5}{ }^{\prime}=0.143$ (exactly equal to the sum of the values $c_{5}$ and $c_{6}$ ). The estimation process was repeated with the renewed expert group. The results are shown in Table 3.

The results of the repeated expertise lead to the following conclusions.

For seven objects (CO, NO, ethanol, formaldehyde, manganese, xylene, toluene), the final value of the consistency coefficient of expert estimates exceeds the application threshold, which means that the estimates are completely consistent.

For the rest of the objects $\left(\mathrm{NO}_{2}\right.$, ammonia, suspended solids, acetic acid, hydrogen fluoride, iron oxide, hydrogen sulfide, petroleum hydrocarbons), the application threshold could not be exceeded, but it was possible to approach it to an adequate degree This allows to calculate the final aggregated estimate with acceptable accuracy. 
Intelligent Analysis of the Ecological State of Environment with Application of... 7

Table 3. Results of the repeated solving the estimation problem.

\begin{tabular}{|c|c|c|c|c|c|}
\hline No. & $\begin{array}{c}\text { Chemical } \\
\text { substances (objects) }\end{array}$ & $\begin{array}{c}\text { Initial consistency } \\
\text { coefficient, } \boldsymbol{K}_{\boldsymbol{S}}(\boldsymbol{W})\end{array}$ & $\begin{array}{c}\text { Final consistency } \\
\text { coefficient, } \boldsymbol{K}_{\boldsymbol{S}}{ }^{\prime}(\boldsymbol{W})\end{array}$ & $\begin{array}{c}\text { Aggregated } \\
\text { estimate } \\
\text { (weight), } \boldsymbol{w}_{\mathbf{0}}\end{array}$ & Rank \\
\hline 1 & $\mathrm{CO}$ & 0,580 & 0,840 & 8,132 & $\mathbf{9}$ \\
\hline 2 & $\mathrm{NO}$ & 0,670 & 0,825 & 9,460 & $\mathbf{8}$ \\
\hline 3 & $\mathrm{NO}_{2}$ & 0,660 & 0,774 & 10,686 & $\mathbf{5}$ \\
\hline 4 & Ammonia & 0,570 & 0,780 & 6,192 & $\mathbf{1 2}$ \\
\hline 5 & Ethanol & 0,562 & 0,847 & 3,400 & $\mathbf{1 5}$ \\
\hline 6 & Suspended solids & 0,470 & 0,570 & 6,382 & $\mathbf{1 0}$ \\
\hline 7 & Formaldehyde & 0,880 & & 13,813 & $\mathbf{1}$ \\
\hline 8 & Acetic acid & 0,480 & 0,746 & 6,245 & $\mathbf{1 1}$ \\
\hline 9 & Hydrogen fluoride & 0,534 & 0,735 & 12,879 & $\mathbf{2}$ \\
\hline 10 & Manganese & 0,563 & 0,818 & 4,095 & $\mathbf{1 3}$ \\
\hline 11 & Iron oxide & 0,569 & 0,710 & 3,528 & $\mathbf{1 4}$ \\
\hline 12 & Hydrogen sulfide & 0,613 & 0,778 & 11,431 & $\mathbf{4}$ \\
\hline 13 & $\begin{array}{c}\text { Petroleum } \\
\text { hydrocarbons }\end{array}$ & 0,456 & 0,678 & 11,568 & $\mathbf{3}$ \\
\hline 14 & Xylene & 0,720 & 0,879 & 9,653 & $\mathbf{6}$ \\
\hline 15 & Toluene & 0,549 & 0,840 & 9,469 & $\mathbf{7}$ \\
\hline \multicolumn{2}{|r|}{$\begin{array}{c}\text { Detection threshold } \\
\text { Application threshold }\end{array}$} & $\begin{array}{c}T_{O}=0,429 \\
U\end{array}$ \\
\hline
\end{tabular}

\section{Application of expertise results to estimate environmental pollution in the districts of Bryansk region}

The resulting aggregated risk estimates of the impact of chemical air pollutants on the environment were used to construct an integral indicators of environmental pollution in accordance with the methodology described in [5]. Table 4 and Fig. 1 show the results of calculating the integral indicator of environmental pollution for various districts of Bryansk region. Along with the indicator of chemical pollution, the results of calculating the indicator of radioactive pollution are presented. The calculation was carried out on the basis of a similar methodology with the expert estimation of the risk of exposure to radioactive substances.

Table 4. Integral indicators of environmental pollution in the districts of Bryansk region.

\begin{tabular}{|c|l|c|c|c|c|}
\hline \multirow{2}{*}{ No. } & \multirow{2}{*}{ Districts } & \multicolumn{4}{|c|}{ Integral indicator of pollution } \\
\cline { 3 - 6 } & & radioactive & rank & chemical & rank \\
\hline 1 & Brasovsky & 0,0225 & 9 & 0,00045 & 12 \\
\hline 2 & Bryansky & 0,0171 & 15 & 0,00223 & 3 \\
\hline 3 & Dubrovsky & 0,0158 & 20 & 0,00037 & 15 \\
\hline 4 & Dyatkovsky & 0,0242 & 8 & 0,04321 & 1 \\
\hline 5 & Gordeyevsky & 0,2031 & 2 & 0,00025 & 17 \\
\hline 6 & Karachevsky & 0,0202 & 12 & 0,00059 & 11 \\
\hline 7 & Kletnyansky & 0,01357 & 28 & 0,00013 & 23 \\
\hline 8 & Klimovsky & 0,07294 & 6 & 0,00001 & 28 \\
\hline
\end{tabular}


8 E. Geger, A. Podvesovskii, O. Mikhaleva, et. al.

Table 4. (Continued).

\begin{tabular}{|c|l|c|c|c|c|}
\hline \multirow{2}{*}{ No. } & \multirow{2}{*}{ Districts } & \multicolumn{3}{|c|}{ Integral indicator of pollution } \\
\cline { 3 - 6 } & & radioactive & rank & chemical & rank \\
\hline 9 & Klintsovsky & 0,1135 & 5 & 0,00018 & 19 \\
\hline 10 & Komarichsky & 0,0216 & 10 & 0,0034 & 4 \\
\hline 11 & Krasnogorsky & 0,20101 & 3 & 0,00011 & 25 \\
\hline 12 & Mglinsky & 0,0044 & 27 & 0,0002 & 26 \\
\hline 13 & Navlinsky & 0,0213 & 11 & 0,00016 & 20 \\
\hline 14 & Novozybkovsky & 0,2800 & 1 & 0,00076 & 7 \\
\hline 15 & Pogarsky & 0,01845 & 14 & 0,0016 & 5 \\
\hline 16 & Pochepsky & 0,00544 & 24 & 0,00043 & 13 \\
\hline 17 & Rognedinsky & 0,015995 & 18 & 0,00016 & 21 \\
\hline 18 & Sevsky & 0,01491 & 22 & 0,00003 & 27 \\
\hline 19 & Starodubsky & 0,03275 & 7 & 0,0004 & 14 \\
\hline 20 & Surazhsky & 0,01496 & 21 & 0,00014 & 22 \\
\hline 21 & Suzemsky & 0,0171 & 16 & 0,00061 & 10 \\
\hline 22 & Trubchevsky & 0,01862 & 13 & 0,00064 & 9 \\
\hline 23 & Unechsky & 0,0159 & 19 & 0,00076 & 6 \\
\hline 24 & Vygonichsky & 0,0162 & 17 & 0,00032 & 16 \\
\hline 25 & Zhiryatinsky & 0,0054 & 25 & 0,00013 & 24 \\
\hline 26 & Zhukovsky & 0,0065 & 23 & 0,00074 & 8 \\
\hline 27 & Zlynkovsky & 0,199 & 4 & 0,00025 & 18 \\
\hline 28 & Bryansk City & 0,00491 & 26 & 0,037 & 2 \\
\hline
\end{tabular}

As can be seen from the presented data, the most chemically contaminated territories are Dyatkovsky district and the city of Bryansk; in terms of the density of radioactive contamination, the following districts are the most contaminated: Novozybkovsky, Gordeevsky, Krasnogorsky, Zlynkovsky, Klintsovsky, Klimovsky, Starodubsky and Dyatkovsky districts.

\section{Conclusion}

The paper considers an approach to the intelligent analysis of ecological situation, based on the application of multi-criteria optimization and technology for supporting group expertise in a distributed environment. An informative and reliable method for estimating anthropo-technogenic pollution of a territory is proposed. It uses integral indicators taking into account environmental pollution. This method was used to assess radioactive and chemical contamination of the districts of Bryansk region. 


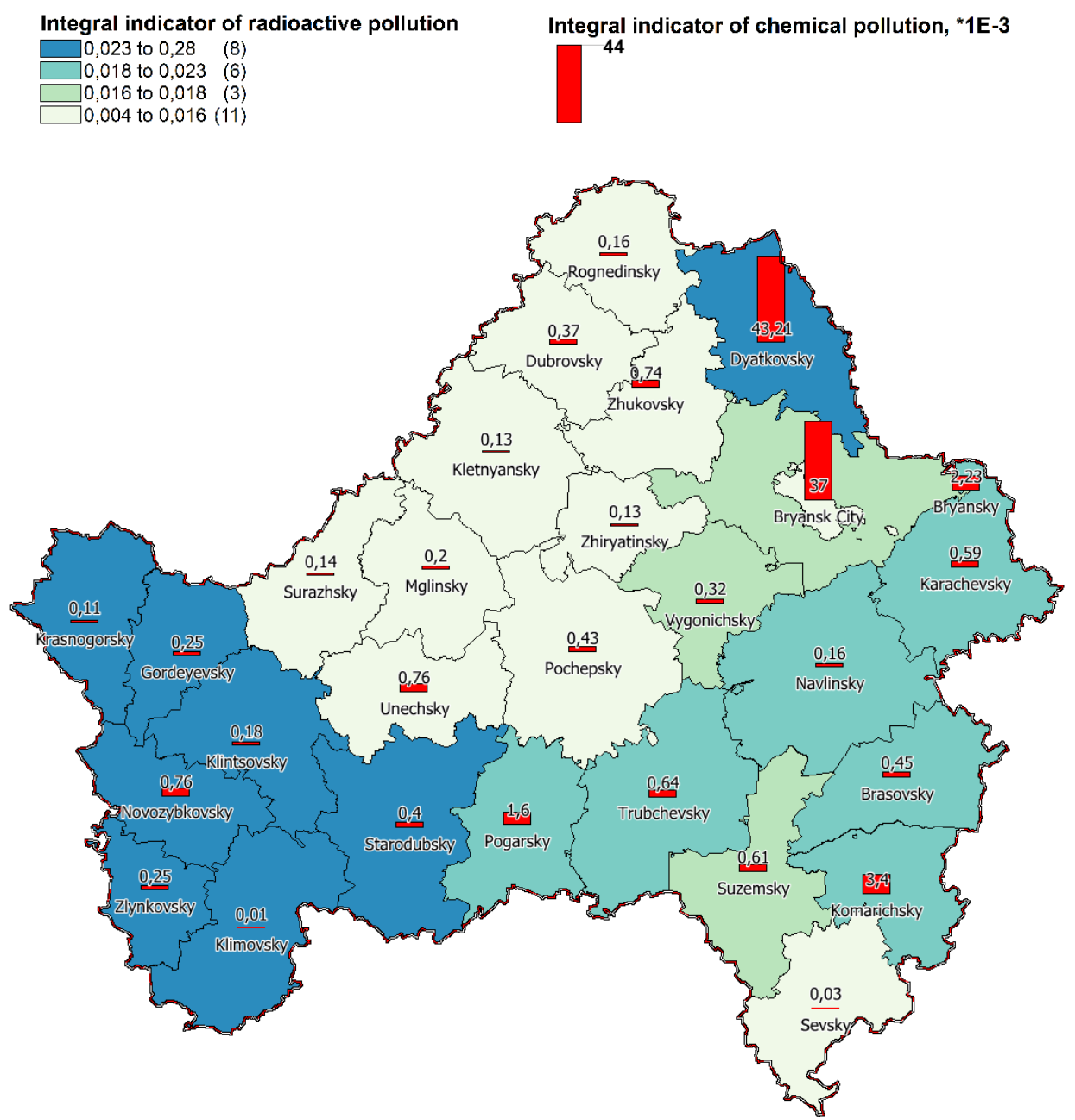

Fig. 1. Displaying indicator values on the map of the Bryansk region.

Expert technologies make it possible to overcome the limitations imposed by methods of statistical data processing as well as those associated with the impossibility of processing heterogeneous environmental and statistical data by traditional methods. Meanwhile, the transition from traditional methods of expert estimation to network ones provides an effective form of distributed interaction among the participants in this process and helps to reduce its total duration. In turn, the use of models and methods for control of expert estimates consistency contributes to an increase in the reliability of estimation results and a decrease in the influence of a random expert error on the final assessment. 
10 E. Geger, A. Podvesovskii, O. Mikhaleva, et. al.

\section{References}

1. Onishchenko, G.G.: O sanitarno-jepidemiologicheskom sostojanii okruzhajushhej sredy [On sanitary and epidemiological state of the environment]. Gigiena i sanitarija [Hygiene and sanitation] 92(2), 4-10 (2013). [in Russian].

2. Popova, A.Yu., Gurvich, V.B., Kuzmin, S.V., Mishina ,A.L., Yarushin, S.V.: Sovremennye voprosy ocenki i upravlenija riskom dlja zdorov'ja [Modern issues of the health risk assessment and management]. Gigiena i sanitarija [Hygiene and sanitation] 96(12), 11251129 (2017). [in Russian]. doi: 10.18821/0016-9900-2017-96-12-1125-1129

3. Geger, E.V.: Jekologicheskaja ocenka vlijanija tehnogennyh nagruzok okruzhajushhej sredy na formirovanie biologicheskih i medicinskih pokazatelej zdorov'ja naselenija (na primere Brjanskoj oblasti) [Environmental assessment of the impact of man-made environmental loads on the formation of biological and medical indicators of public health (on the example of the Bryansk region)] (Sc.D. in Biology Thesis), Bryansk: Bryansk State University (2014). [in Russian].

4. Gubanov, D., Korgin, N., Novikov, D., Raikov, A.: E-Expertise: Modern Collective Intelligence. Springer International Publisher (2014). doi: 10.1007/978-3-319-06770-4

5. Geger, E.V.: Metodologija razrabotki integral'nogo pokazatelja zagrjaznenija dlja ocenki jekologicheskogo sostojanija okruzhajushhej sredy [The Methodology of Development of Integral Indicator to Assess the Environmental Pollution]. Perspektivy nauki [Science Perspectives] 5(32), 190-193 (2012). [in Russian].

6. Geger, E.V., Zolotnikova, G.P.: Vlijanie radiacionnyh i himicheskih nagruzok na izmenenija biohimicheskih pokazatelej jendokrinnogo gomeostaza u zhitelej iz jekologicheski razlichnyh rajonov Brjanskoj oblasti [Influence of Radiating and Chemical Loads on Changes of Biochemical Indices of the Endocrine Homeostasis in Inhabitants from Ecologically Various Areas of the Bryansk Region]. Gigiena i sanitarija [Hygiene and sanitation] 95(5), 428-432 (2016). [in Russian]. doi: 10.18821/0016-9900-2016-95-5-422-428

7. Cai, J.: A social interaction analysis methodology for improving E-collaboration over the Internet. Electronic Commerce Research and Applications, 4(2), 85-99 (2005). doi: 10.1016/j.elerap.2004.10.007

8. Podvesovskii, A.G., Mikhaleva O.A.: Tehnologija podderzhki gruppovoj jekspertizy v raspredelennoj srede [Technology for Group Expertise Support in Distributed Environment]. XXI vek: itogi proshlogo i problemy nastojashhego pljus [XXI Century: Resumes of the Past and Challenges of the Present plus] 8(4), 20-25 (2019). [in Russian].

9. Podvesovskii, A., Mikhaleva O., [et. al.]: A Model of Control of Expert Estimates Consistency in Distributed Group Expertise. In: Kravets, A. et. al. (eds.) CIT\&DS 2017, CCIS, vol. 754, pp. 361-374. Springer International Publishing AG (2017). doi: 10.1007/978-3319-65551-2_26

10. Totsenko, V.G.: Spectral Method for Determination of Consistency of Expert Estimate Sets. Eng Simulat 17, 715-727 (2000). 